\title{
Attentional impairment and minor physical anomalies in early onset schizophrenia
}

Deyashini Lahiri, Amool Ranjan Singh, Ranchi Institute of Neuro Psychiatry

and Allied Sciences, Kanke, Ranchi

\section{ABSTRACT}

Background : Minor physical anomalies (MPAs) are established markers of abnormal neurodevelopment that also has been postulated to lead to attentional impairments. Both these variables are studied and found in schizophrenia. We aimed to compare the neuropsychological domain of attention in patients with schizophrenia and healthy controls and correlated the findings with number of MPAs. Methods : Thirty patients with early onset schizophrenia (in remission) and thirty healthy controls were recruited. While attention was assessed using the Digit span, the Digit vigilance and the Trail Making Tests, MPAs were comprehensively assessed using the 55 item Extended Waldrop Scale. Study variables were analysed using non-parametric measures. Results : Schizophrenia patients were found to have significantly higher cranio facial and total MPAs. Attentional impairment in patients was significantly impaired as compared to controls. There was no significant correlation between MPA scores and attentional measures. Conclusions : This study supports the finding that total and specific cranio-facial MPA scores and, impaired attention are indeed illness markers in schizophrenia patients. No distinguishable association, however, was found between MPAs and attentional measures. We suggest heterogeneity in brain morphogenesis, disease and treatment influences as possible hindrances.

Keywords : Schizophrenia; Neurodevelopment; Neuropsychology; Minor physical anomalies; attention.

\section{INRODUCTION}

There is a recent trend amongst the

\section{Corresponding Author}

Deyashini Lahiri Ranchi Institute of Neuro

Psychiatry and Allied Sciences, Kanke,

Ranchi, Jharkhand,

Email : deyashini.lahiri@gmail.com schizophrenia researchers to identify composite risk-markers in order to adequately support the current criterion (symptom) based diagnosis of the disorder. Risk marker identification essentially is known to help discover complex genetic mechanisms underlying the etiology of a given disorder (Gottesmanand Gould, 2003). Researchers have included clinical, morphological, neuroanatomical, neurophysiological, neuro-pathological and neurological parameters for their studies. Much of such research on schizophrenia in the last two decades is primarily based upon the Neuro-developmental hypothesis (Murray et al., 1992; Weinberger, 1987; Woods, 1998) (illustrated 


\section{Lahiri, et al.: Attentional impairment, early onset schizophrenia}

briefly in figure 1). Neurodevelopmental models of schizophrenia can be subdivided into two categories: early and late. Early neurodevelopmental models propose that early brain damage, such as prenatal lesions of the temporal lobe, are followed by extensive "rewiring" of neural circuitry in subsequent development, leading to misconnections which to the chronological order of the normal embryonic development (Tarrant and Jones, 1999). Though the pathogenesis of these anomalies could not be clearly specified, they appear to be the result of a combined interaction between inherited genetic defects, chromosomal aberrations, early pregnancy complications and environmental teratogenic

Figure 1

\section{NEURODEVELOPMENTAL HYPOTHESIS}

\section{Endogenous (genetic) or exogenous (environmental) insult during fetal development} $\downarrow$ Triggers

Anomalous development of ectoderm

MPAs

$\downarrow$

$\downarrow$ Triggers

Cell necrosis

$\downarrow$

Inflammation and gliosis

$\downarrow$ $\downarrow$

Cell changes in CNS

$\downarrow$ Triggers

Apoptosis

$\downarrow$

Cell death without gliosis

$$
\downarrow
$$

\section{Neuroanatomical changes (ventricular enlargement, cortical atrophy etc) \\ $\downarrow$ \\ $\downarrow$}

Neurological (NSS),
Neurobehavioral abnormalities (positive and negative symptoms) Neuropsychological abnormalities are thought to underlie the disorder (Goodman, 1989). Late neurodevelopmental models suggest that the ongoing processes of brain maturation that continues well into adolescence is itself abnormal in schizophrenia.

Central nervous system and superficial connective tissue develop from ectoderm in utero, hence the early or the prenatal brain damage described in early neurodevelopmental models are associated with a range of minor alterations in the development of various physical structures as well. Among these alterations are minor physical anomalies (MPAs), an MPA is an insignificant physical defect, a deviation in appearance from essential physical characteristics (Evans et al., 1973). Because of their relation to development of central nervous system, MPAs can be used as biological markers in tracking down developmental disturbances timed according agents through some unknown mechanisms (Jones and Murray, 1991). Numerous studies have compared the incidence ofMPAs are in patients with schizophrenia and the healthy population.

Relationship of MPAs with various neuropsychological correlates has been studied (see table - 1). From table - 1 we infer that MPAs have an arguable relationship with neuropsychological variables. Amongst the significant relationships with the neuropsychological tests specific deficits in attention, concentration, vigilance and working memory in general are indicated which point to frontal lobe dysfunction.

In this study we compared the neuropsychological domain of attention in patients with schizophrenia and healthy controls and correlated the findings with number of MPAs assessed using a comprehensive list. 


\section{METHODS}

The study had the approval of the Institute Ethics Committee of Ranchi Institute of Neuro-Psychiatry and Allied Sciences (RINPAS), Ranchi, India. Written informed consent was obtained from all the subjects (and their legally qualified representatives in case of patients) after explaining them fully about the procedures and then enrolled into the study.

\section{SUBJECTS}

\section{PATIENTS}

Thirty patients (16 male) of schizophrenia were recruited into the study by purposive sampling from those who attended the outpatient services of RINPAS. The inclusioncriteria were a International Classification of Diseases diagnosis- diagnosis and research criteria ICD (DCR)-10 (World Health Organization, 1992) diagnosis of schizophrenia with duration of illness less than 2 years and fulfilling the operational criteria for remission,right handedness, age between 18 and 25 years and average IQ. The exclusion criteria were any history of neurological illness or significant head injury, presence of co-morbid substance dependence or any other psychiatric disorder, disruptive behavior (suicidal or homicidal) that warranted immediate interventions, and history of electroconvulsivetherapy within the previous 6 months.

\section{CONTROLS}

Thirty healthy individuals (18 male) in the same age group as the patients (18-25 years) were recruited. These subjects, predominantly constituted by relatives of hospital staffand public in the immediate locality of the hospital were administered general health questionnaire (GHQ)-12 (Goldberg and William) which warranted a score of above 3 . Presence of any history of neurological illness or significant head injury, substance dependence or any psychiatric disorder and history of psychotic disorders in their first-degree relatives were the exclusion criteria.

\section{CLINICAL ASSESSMENTS}

Handedness was assessed using Handedness preference schedule (HPS) - Hindi version (Mandal et al., 1992). The baseline schizophrenia psychopathology severity was evaluated by administering the Positive and

Table-1 : List of studies associating MPAs with neuropsychological correlates in schizophrenia

\begin{tabular}{|c|c|c|c|}
\hline $\begin{array}{c}\text { Serial } \\
\text { no }\end{array}$ & Studies & Correlates studied & Results/Inferences \\
\hline 1 & Guy et al. (1983) & $\begin{array}{l}\text { Chronicity of illness, premorbid } \\
\text { adjustment, Wechsler Adult } \\
\text { Intelligence Scale and } \\
\text { Neurological Impairment } \\
\text { Index }\end{array}$ & $\begin{array}{l}\text { Significant relationship } \\
\text { with the subset of premorbid } \\
\text { adjustment, } \\
\text { Vocabulary scores on Wechsler Adult } \\
\text { Intelligence Scale, } \\
\text { and Neurological Impairment } \\
\text { Index }\end{array}$ \\
\hline 2 & $\begin{array}{l}\text { Green } \\
\text { al.(1989) }\end{array}$ & $\begin{array}{l}\text { Age of onset, tests of vigilance, } \\
\text { attention and orientation }\end{array}$ & Association only with age of onset. \\
\hline 3 & $\begin{array}{l}\text { O'Callaghan } \\
\text { et al. (1991) }\end{array}$ & $\begin{array}{l}\text { Age of onset, family history, } \\
\text { birth related complications, } \\
\text { sex, trail making test }\end{array}$ & $\begin{array}{l}\text { Linear multiple regression analysisshowed } \\
\text { that higher scores for minor physical } \\
\text { anomalies were associated withimpaired } \\
\text { cognitive flexibility on Trail Making Test B, } \\
\text { family history ofschizophrenia in a first- }\end{array}$ \\
\hline
\end{tabular}




\begin{tabular}{|c|c|c|c|}
\hline & & & $\begin{array}{l}\text { degree relative, maternal history of } \\
\text { obstetriccomplications, smaller number of } \\
\text { siblings, later position in the birthorder, and } \\
\text { male sex. A family history of schizophrenia } \\
\text { was particularlyassociated with abnormalities } \\
\text { of the mouth. The association between } \\
\text { minorphysical anomalies in the patients and } \\
\text { obstetric complications in theirmothers } \\
\text { appeared to be confined to instances in which } \\
\text { the mother had ahistory of bleeding in early } \\
\text { pregnancy. }\end{array}$ \\
\hline 4 & 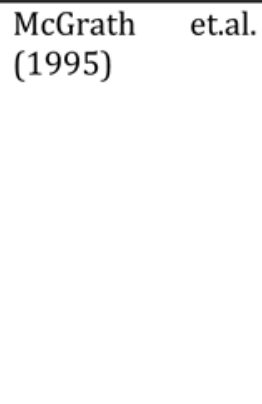 & $\begin{array}{l}\text { Gender, age at onset, negative } \\
\text { symptoms,prernorbid level of } \\
\text { functioning, } \\
\text { estimated premorbid } \\
\text { intelligence (NART, WAIS), } \\
\text { pregnancy and birth } \\
\text { complications, and selected CT } \\
\text { variables (total volume of } \\
\text { lateral ventricle, maximum } \\
\text { volume of the third ventricle) }\end{array}$ & No associations \\
\hline 5 & $\begin{array}{l}\text { O'Callaghan } \\
\text { et al. (1995) }\end{array}$ & $\begin{array}{l}\text { Positive } \text { and } \quad \text { negative } \\
\text { symptoms, neuropsychological } \\
\text { tests, MRI }\end{array}$ & No correlation \\
\hline 6 & $\begin{array}{l}\text { Ismail et al. } \\
(2000)\end{array}$ & $\begin{array}{l}\text { Premorbid personality, age of } \\
\text { onset, severity, } \\
\text { neuropsychological test scores } \\
\text { (word pair } 1 \text { and 2, trail } \\
\text { making A and B digit span } 1 \\
\text { and 2, verbal fluency and } \\
\text { Wisconsin card sort test } \\
\text { categories and preservative } \\
\text { errors), }\end{array}$ & No correlation \\
\hline
\end{tabular}

Negative Syndrome Scale (PANSS) (Kay et al., 1987). The criteria for remission used for this study was the modification of the proposed multidimensional criteria for symptomatic remission by Andreasen et al. (2005). Mild or lower severity ( $\leq 3$ ) on all relevant items at the point of selection i.e.

1. For the dimension of reality distortion the selected PANSS items are P1 (delusions), P3 (hallucinatory behavior), and G9 (unusual thought content).

2. For the dimension of disorganization they are P2 (conceptual disorganization) and G5 (mannerisms/posturing).
3. For the dimension of negative symptoms they are N1 (blunted affect), N4 (social withdrawal), and N6 (lack of spontaneity).

\section{ASSESSMENT OF MPAs}

A modified version of the Waldrop scale-Extended Waldrop scale (Mehes, 1988) was used for the assessment of MPAs. All of the items were used in this study except for measuring the mandible size which needs a specialized occipito-mental view in X-ray mandible. Total number of MPAs assessed was 54 . All items were scored as present or absent only. Only one researcher assessed and rated the items. However, inter-rater reliability of the scale is found to be high (Trixler et al., 1997). 
Lahiri, et al. : Attentional impairment, early onset schizophrenia

\section{TOOLS FOR NEUROCOGNITIVE MEASURES :}

\author{
Digit Span Test (Subtest of WAIS-III; \\ Wechsler, 1997) :
}

Digit span tasks have been commonly used to assess attention and working memory in both clinical and nonclinical populations. The WAIS-III, Digit Span subtests require oral presentation of digits. For clinical applications, the traditional method of administration is oral. The split half reliability of the test was .90 and test retest reliability was .83 . This was also found to have highest specificity of WAIS III subtest .50/.10 (Kaufman \& Lichtenberger, 1999). Digit span demonstrated moderate criterion validity while correlated with Stanford Binet Composite score $(\mathrm{r}=.48)$.

\section{Digit Vigilance Test (Lezak, 1995) :}

This test is a measure of vigilance. This is the ability to maintain attention and alertness overprolonged periods of time.It consists of number 1 to 9 randomly ordered and placed in rows on a page.Different digits are arranged in rows. There are 30 digits per row and 50 rows on the sheet. Subjects are asked to cancel digit 6 and 9 only by using ' $/$ '. So, the subject has to focus on the target digits 6 and 9 amongst other distracter digits. They were also asked to finish the task as fast as possible. Scoring was done by considering the time to complete the test and by calculating the error score. The error score is the sum total of the number of omission of digit 6 and 9 those were not cancelled. Another type of error score was the sum total of the digits cancelled other than target digits. It takes 15 minutes to complete.

\section{Trail Making Test (Reitan, 1956) :}

It was developed by Reitan (1956). Although trail making tests are very simple, they have been hypothesized to reflect a wide variety of cognitive processes including attention, visual search and scanning, sequencing and shifting, psychomotor speed, abstraction, flexibility, ability to execute and modify a plan of action, and ability to maintain two trains of thought simultaneously. This test demands adequate visual scanning, selective attention and cognitive set shifting during an easy task. The test has two parts; part ' $\mathrm{A}$ ' and part ' $\mathrm{B}$ '. Part ' $\mathrm{A}$ ' requires the subjects to connect 25 numbered circles (in increasing order) with the help of pencil. In part ' $\mathrm{B}$ ' 13 circles are numbered 1-13 and rest 12 are marked A-L. Subjects must alternate between digits and letters. Approximately 5-10 minutes required to finish the test. Reliability was reported as .98 for part A and .67 for part B (Lezak, 1983).

\section{Statistical analysis}

Sample demographic and clinical characteristics were determined using frequencies and mean (standard deviation) and, were compared between the two groups using independent samples $t$ test and chi square test. MPAs and neuropsychological variables were compared using Mann-Whitney U test. Spearman's correlation was used for assessing the association between MPAs and attentional measures.

\section{RESULTS}

Table 2 shows the comparison of socio demographic variables between the two groups. It is found that both groups are comparable on age, gender, education, socioeconomic status and habitat. However, compared to the patient group, significantly higher numbers of subjects in the control group were unmarried students belonging to religion other than Hinduism. The mean illness duration was $14.77 \pm 5.96$ months. The remitted patients were on antipsychotic drugs and the mean chlorpromazine equivalent dose was $268.33 \pm 96.03$. On comparison of MPAs between the two groups it was found that MPAs in skull, eyes, ears, mouth and the total score were significantly higher in the patients (Table 3). Scores on the Digit Span test, time taken to complete and number of omission errors on digit vigilance task were significantly impaired in patients. On the TMT, only time on ' $A$ ' subtest and both time and errors on ' $\mathrm{B}$ ' subtest were significantly higher in the 


\section{Lahiri, et al.: Attentional impairment, early onset schizophrenia}

patient group (Table 3). Table 4 shows that there is no significant correlation between MPA scores and attentional measures.

\section{DISCUSSION}

This study supports the finding that total and regional MPA scores, assessed using the EWS, are significantly higher in schizophrenia patients compared to healthy controls. The topographical distribution of MPAs in schizophrenia can unravel the temporal course and nature of abnormal neurodevelopment. Regional analysis in our study showed that MPAs in cranio-facial region- skull, eyes, ears and mouth significantly higher in the patient group than the control group, where as MPAs elsewhere- limbs and trunk did not show significant difference.This is consistent with other studies that show specific cranio-facial MPAs may be associated with schizophrenia (Compton et al., 2011).

In the domain of attention, patients with schizophrenia were found to be significantly poorer than healthy control as indicated by lower digit forward and backward scores, higher number of omission errors and time

Table 2 : Sample Characteristics

\begin{tabular}{|c|c|c|c|c|c|c|}
\hline & & $\begin{array}{c}\text { Schizophrenia } \\
\text { Patient } \\
(\mathrm{N}=30)\end{array}$ & $\begin{array}{l}\text { Control } \\
(\mathrm{N}=30)\end{array}$ & $t / x^{2}$ & df & $\mathbf{P}$ \\
\hline \multicolumn{7}{|l|}{ Age (years) } \\
\hline mean $\pm \mathrm{SD}$ & & $22.97 \pm 2.19$ & $22.70 \pm 1.54$ & 0.55 & 58 & .59 \\
\hline \multirow[t]{2}{*}{ Gender } & Male & 16 & 18 & 0.27 & 1 & .60 \\
\hline & Female & 14 & 12 & & & \\
\hline \multirow[t]{2}{*}{ Marital status } & Married & 9 & 2 & $5.45^{*}$ & 1 & .02 \\
\hline & Unmarried & 21 & 28 & & & \\
\hline \multirow[t]{2}{*}{ Religion } & Hindu & 27 & 18 & $7.20^{* *}$ & 1 & .007 \\
\hline & Others & 3 & 12 & & & \\
\hline \multicolumn{7}{|l|}{ mean $\pm \mathrm{SD}$} \\
\hline \multirow[t]{3}{*}{ Occupation } & Employed & 6 & 2 & $9.79^{* *}$ & 2 & .007 \\
\hline & Unemployed & 13 & 5 & & & \\
\hline & Student & 11 & 23 & & & \\
\hline \multirow[t]{3}{*}{ Socio-Economic Status } & Lower & 19 & 12 & 3.33 & 2 & .19 \\
\hline & Middle & 9 & 14 & & & \\
\hline & Higher & 2 & 4 & & & \\
\hline \multirow[t]{2}{*}{ Residence (\%) } & Rural & 14 & 20 & 3.72 & 1 & .16 \\
\hline & Urban & 16 & 10 & & & \\
\hline \multirow[t]{2}{*}{ Past medical illness (\%) } & Significant & 3 & 2 & 0.22 & 1 & .64 \\
\hline & Insignificant & 27 & 28 & & & \\
\hline \multirow{2}{*}{$\begin{array}{l}\text { Family psychiatric } \\
\text { illness (\%) }\end{array}$} & Significant & 9 & - & - & - & - \\
\hline & Insignificant & 21 & - & & & \\
\hline $\begin{array}{l}\text { Family medical illness } \\
(\%)\end{array}$ & Significant & 4 & 5 & 0.13 & 1 & .72 \\
\hline
\end{tabular}


Lahiri, et al. : Attentional impairment, early onset schizophrenia

\begin{tabular}{|llll|}
\hline $\begin{array}{l}\text { Illness duration } \\
\text { (months) } \\
\text { mean } \pm \text { SD }\end{array}$ & Insignificant & 26 & 25 \\
$\begin{array}{l}\text { Drug dosage } \\
\text { Chlorpromazine } \\
\text { equivalents } \\
\text { mean } \pm \text { SD }\end{array}$ & $14.77 \pm 5.96$ & - & \\
PANSS & & \\
mean \pm SD & $268.33 \pm 96.03$ & - & \\
& Positive & $8.07 \pm 1.23$ & - \\
& syndrome & & \\
& Negative & $8.47 \pm 1.46$ & - \\
& syndrome & & \\
& General & $19.43 \pm 3.63$ & - \\
Total & $36.30 \pm 5.55$ & - \\
\hline
\end{tabular}

${ }^{*} \mathrm{p}<.01 ;{ }^{* *} \mathrm{p}<.01$; PANSS- Positive and Negative Syndrome Scale; SD- Standard Deviation

Table 3 : Comparison of study variables across schizophrenia patients and healthy controls

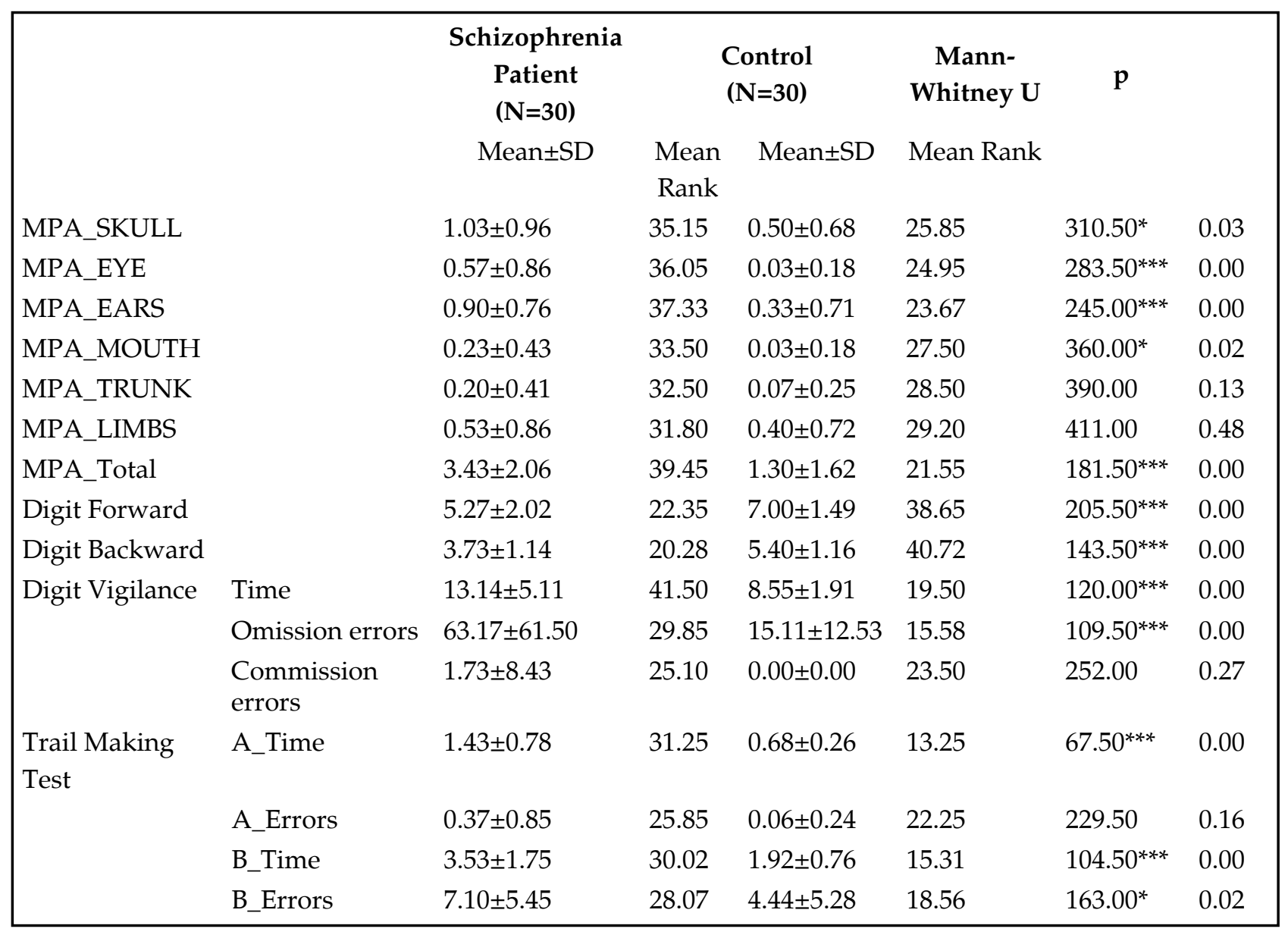

${ }^{*} \mathrm{p}<.05 ;{ }^{* * *} \mathrm{p}<.001 ; \mathrm{MPA}$ - Minor Physical Anomalies; SD - Standard Deviation 
taken to complete digit vigilance task. Earlier studies (CornblattandKeilp, 1994; Everett et al., 1989; Green and Walker, 1986) on attention in schizophrenia were found to be consistent with the result of the study. In a recent study, Kim et al. (2011) concluded that domain of attention as part of overall neurocognition in schizophrenia was found to beworst than healthy control, so the finding of this study. Also similar to our study results, a longitudinal study by SanchezTorres et al. (2013) showed that the schizophrenia spectrum disorder patients differed significantly from healthy controls in their performance on the Trail Making Test.

No significant relationship was found between rates of MPAs and attentional

\section{Table 4 : Correlation between MPAs and measures of attention}

\begin{tabular}{|c|c|c|c|c|c|c|c|c|c|}
\hline \multirow{2}{*}{$\begin{array}{c}\text { Spearman's } \\
\text { Correlation } \\
\text { rho }\end{array}$} & \multirow{2}{*}{$\begin{array}{c}\text { Digit } \\
\text { Forward }\end{array}$} & \multirow{2}{*}{$\begin{array}{c}\text { Digit } \\
\text { Backward }\end{array}$} & \multicolumn{4}{|c|}{ Digit Vigilance } & \multicolumn{3}{|c|}{ Trail Making Test } \\
\hline & & & Time & $\begin{array}{l}\text { Omission } \\
\text { errors }\end{array}$ & $\begin{array}{l}\text { Commiss- } \\
\text { ion errors }\end{array}$ & $\begin{array}{c}\text { A_ } \\
\text { Time }\end{array}$ & $\begin{array}{c}\mathrm{A}_{-} \\
\text {Errors }\end{array}$ & $\begin{array}{c}\mathrm{B}_{-} \\
\text {Time }\end{array}$ & $\begin{array}{c}\mathrm{B}_{-} \\
\text {Errors }\end{array}$ \\
\hline MPA_SKULL & -0.310 & -0.189 & 0.130 & 0.096 & -0.018 & -0.093 & 0.210 & 0.275 & -0.201 \\
\hline MPA_EYE & -0.074 & -0.216 & -0.262 & -0.140 & 0.185 & 0.079 & -0.064 & 0.191 & -0.040 \\
\hline MPA_EARS & 0.014 & -0.092 & -0.118 & -0.075 & 0.013 & -0.203 & -0.260 & -0.096 & -0.351 \\
\hline MPA_MOUTH & -0.102 & -0.147 & 0.077 & 0.159 & 0.179 & 0.264 & 0.300 & 0.281 & 0.075 \\
\hline MPA_TRUNK & 0.196 & -0.221 & -0.075 & 0.029 & 0.211 & -0.159 & -0.062 & -0.222 & 0.030 \\
\hline MPA_LIMBS & -0.241 & -0.272 & 0.130 & -0.159 & 0.053 & -0.013 & 0.104 & 0.298 & -0.170 \\
\hline MPA_Total & -0.235 & -0.275 & -0.084 & -0.064 & 0.332 & -0.113 & 0.082 & 0.339 & -0.253 \\
\hline
\end{tabular}

${ }^{*} \mathrm{p}<.05 ;{ }^{* *} \mathrm{p}<.01 ; \mathrm{MPA}-$ Minor Physical Anomalies

dysfunction in the patients. Further, as in most previous investigations of clinical correlates of MPAs (see Table 1), clinical impairment was not related to rates of MPAs in the patients. Thus, higher number of MPAs would not allow the identification of a separate distinguishable subgroup among patients as proposed by Murray et al. (1992) in their 'congenital' model. However, the simultaneous occurrence of increased rates of both MPAs and attentional dysfunction in patient sample suggests a possible role of one or more 'congenital' factors in the etiological underpinnings of schizophrenia patients.

The lack of association between MPAs and attention measures could have resulted from low statistical power in within-group analyses of relatively small samples (i.e. 30 vs. 30 patients) and using nonparametric analyses. A number of other explanationsfor the lack of statistical significance are possible: the early brain dysmorphogenesisseen in schizophrenia is multifactorial in origin (Tikka et al., 2014) and might have obscured the specific relationship between MPAs and attentional characteristics. Also, the operational assessment of MPAs may not adequately measure parallel maldevelopment in the brain. One possible future research strategy would be the study of different disease characteristics in relation to individual MPA items which have high discriminative power in schizophrenia samples. And, subsequent development of the brain could provide great variation in the manifest level or type of attention characteristics of schizophrenia patients in adulthood (Waddington and Buckley, 1996). There is a possibility of contamination by other factors such as later environmental influences, disease and recovery processes (as patients were in remission), the schizophrenia process itself, its treatment etc. 


\section{Lahiri, et al. : Attentional impairment, early onset schizophrenia}

Despite negative findings with respect to attentional correlates of MPAs, the current study's major strength is the use of an extended MPA battery (55 items) to investigate relationships between MPAs and other characteristics of schizophrenics. To the best of the authors' knowledge, although used in Indian population (Tikka et al., 2013), it is the first study to use this tool for correlation with neuropsychological variables. Moreover, inclusion of early onset schizophrenia patients in the present study is particularly crucial while explaining neurodevelopmental basis as the period of onset of psychosis is related to over pruning of synaptic connections (Feinberg, 1982).

\section{CONCLUSION}

The present study reiterates the finding of higher developmental anomalies in patients with schizophrenia in comparison with healthy controls and also restates the profound attentional neurocognitive impairment in them. The study however, fails to show a significant relationship between rates of MPAs and attentional dysfunction in the patients. We suggest heterogeneity in brain morphogenesis, incapability of MPA assessment alone MPAs to measure parallel maldevelopment and later life environmental, disease and treatment influences as possible hindrances for a possible association apart from statistical shortcomings of the study.

\section{REFERENCES}

Andreasen, N.C., Carpenter, W.T., Kane, J.M., Lasser, R.A., Marder, S.R., Weinberger, D.R. (2005).Remission in schizophrenia: proposed criteriaand rationale for consensus. American Journal of Psychiatry, 162, 441-449.

Compton, M.T., Chan, R.C.K., Walker, E.F., Buckley, P.F. (2011). Minor physical anomalies: potentially informative vestiges of fetal developmental disruptions in schizophrenia. International Journal of Developmental Neuroscience 29, 245-250.

Cornblatt, B.A., Keilp, J.G. (1994). Impaired attention, genetics, and thepathophysi -ology of schizophrenia.Schizophrenia Bulletin, 20, 31-46.

Evans, J.R., Goldstein, M.J., Rodnick, E.H. (1973).Premorbid adjustment, paranoid diagnosis and remission.Archives of General Psychiatry, 28, 666-672.
Everett, J., Laplante, L., Thomas, J. (1989). The selective attention deficit inschizophrenia.Limited resources or cognitive fatigue?JournalofNervous and Mental Disorders, 177, 735-738.

Feinberg I. (1982). Schizophrenia: caused by a fault in programmed synaptic elimination during adolescence? Journal of Psychiatric Research, 17, 319-334.

Goldberg, D.P., William, P. (1998).A user guide to general health questionnaire. Windsor NFER.Nelson.

Goodman, R. (1989).Neural misconnections and psychiatric disorder. Is there a link? British Journal of Psychiatry, 154, 292-299.

Gottesman, I.I., Gould, T.D. (2003). The endophenotype concept in psychiatry: etymology and strategic intentions. American Journal of Psychiatry, 160, 636-645.

Green, M.F., Satz, P., Gaier, D.J., Ganzell, S., Kharabi, F.(1989). Minor physical anomalies in schizophrenia. Schizophrenia Bulletin, 15, 91-99.

Green, M.F., Walker, E. (1986). Attentional performance in positive- andnegative-symptom schizophrenia. Journal of Nervous and MentalDisorders,174, 208-213.

Guy, J.D., Majorski, L.V.,Wallace, C.J., Guy, M.P. (1983). The incidence ofminor physical anomalies in adultmale schizophrenics.Schizophrenia Bulletin, 9, 571-582.

Ismail, B., Cantor-Graae, E., McNeil, T.F. (2000). Minor physical anomalies in schizophrenia: cogitive, neurological and other clinical correlates. Journal of Psychiatric Research, 34, $45-56$.

Jones, P.B., and Murray, R.M. (1991). The genetics of schizophrenia is the genetics of neurodevelopment. British journal of psychiatry, 158, 615-623.

Kaufman, A.S., Lichtenberger, E. O. (1999). Essentials of WAIS IIIAssessment. New York: Wiley and Sons.

Kay, S.R., Opler, L.A.,Lindenmayer, J.P. (1987).The Positive and Negative Syndrome Scale (PANSS) for schizophrenia. Schizophrenia Bulletin, 13, 261-276.

Kim, H.S., Shin, N.Y., Jang, J.H., Kim, E., Shim, G., Park, H.Y., Hong, K.S., Kwon, J.S. (2011). Social cognition and neurocognition as predictors ofconversion to psychosis in individuals at ultra-high risk.SchizophreniaResearch, 130, 170-175.

Lezak, M. D. (1983). Neuropsychological assessment (2nd edn.). New York:Oxford University Press.

Lezak, M.D. (1995). Neuropsychological Assesment (3rd edition), New York : Oxford University Press.

Mandal, M.K., Pandey, G., Singh, K.S., Asthana, S.H. (1992).Hand preference in India.International journal of psychology, 27, 433-442.

McGrath, J.J., van Os, J., Jones, P.B., Harvey, I., Murray, R.M., (1995). Minor physical anomalies in psychosis : associations with clinical and putative aetiological variables Schizophrenia Research, 18, 9-20.

Mehes, K. (1988) Informative morphogenetic variants in the newborn.Akademia -iKiado, Budapest.In Trixler, M., Tenyi, T., Csabi, G., Sxabo, R. (2001) Minor physical anomalies in 


\section{Lahiri, et al.: Attentional impairment, early onset schizophrenia}

schizophrenia and bipolar affective disorder.Schizophrenia Research, 52, 3, 195-201.

Murray, R.M., O'Callaghan, E., Castle, D.J., Lewis, S.W. (1992). A neurodevel -opmental approach to the classification of schizophrenia.Schizophrenia Bulletin, 18, 319-332.

O'Callaghan, E., Buckley, P., Madigan, C., Redmond, O., Stack, J.P., Kinsella, A., Larkin, C., Ennis, J.T., Waddington, J.L. (1995).The relationship of minor physical anomalies and other putative indices of developmental disturbance in schizophrenia to abnormalities of cerebral structure on magnetic resonance imaging.Biological Psychiatry, 38, 516-524.

O'Callaghan, E., Larkin, C., Kinsella, A., Waddington, J.L. (1991). Familial, obstetric, and other clinical correlates of minor physical anomalies in schizophrenia.American Journal of Psychiatry, 148, 479-483.

Reitan, R.M. (1956). Trail Making Test: Manual for administration, scoring andinterpretation. Mimeo: Indiana University Press.

Sánchez-Torres, A.M., Basterra, V., Moreno-Izco, L., Rosa, A., Fañanás, L.,Zarzuela, A., Peralta, V., Cuesta, M.J. (2013). Executive functioning inschizophrenia spectrum disorder patients and their unaffected siblings: Aten-year follow-up study. Schizophrenia Research, 143, 291-296.

Tarrant, C.J., Jones, P.B. (1999) Precursors to schizophrenia: do biological markers have specificity. Canadian Journal Psychiatry, 44, 335-349.
Tikka, S.K., Yadav, S., Nizamie, S.H., Das, B., Goyal, N., Tikka, D.L.(2014). Sporadic and familial subgroups of schizophrenia do not differ on dense array spontaneous gamma oscillatory activity.Psychiatry Research (In Press;doi : 10.1016/j. psychres.2014.08.042).

Tikka, S.K., Nizamie, S.H., Das, B., Katshu, M.Z.U.H., Goyal, N.(2013). Increased spontaneous gamma power and synchrony in schizophrenia patients having higher minor physical anomalies. Psychiatry Research, 207, 164-172.

Trixler, M., Tényi, T., Csábi, G., Szabó, G., Méhes, K. (1997). Informative morphogenetic variants in patients with schizophrenia and alcohol-dependant patients: beyond the Waldrop scale. American Journal of Psychiatry, 154, 691693.

Waddington, J.L., Buckley, P.F. (1996). The neurodevelopmental basis of schizophrenia.Springer: Heidelberg.

Wechsler, D. (1997). WAIS-III administration and scoring manual. SanAntonio, TX: The Psychological Corporation.

Weinberger,D.R.(1987).Implications of normalbrain development for the pathogenesis of schizophrenia.Archives of General Psychiatry, 44, 660-669.

Woods, B.T. (1998). Is schizophrenia a progressive neurodevelopmental disorder? Toward a unitary pathogenetic mechanism. American Journal of Psychiatry, $155,1661-1670$.

World Health Organization. (1992) The ICD-10 classification of mental and behavioural disorders: Diagnostic criteria for research. Geneva: WHO. 